\title{
Design and Methodology of Automated Guided Vehicle-A Review
}

\author{
Suman Kumar Das ${ }^{1}$, M.K.Pasan ${ }^{2}$ \\ ${ }^{1}$ (Department of Mechanical Engineering, NIT Jamshedpur, INDIA) \\ ${ }_{2}^{2}$ (Professor, Department of Mechanical Engineering, NIT Jamshedpur, INDIA)
}

\begin{abstract}
In this paper, we study the design and different methodology of automated guided vehicle $(A G V)$ systems. This paper provides an overview on AGVS technology discusses recent technological developments and describes the formulation to control the traffic inside industrial work space.
\end{abstract}

Keywords - AGV, Automation, Material handling, line follower AGV.

\section{INTRODUCTION}

Material handling is defined by MHIA (MATERIAL HANDLING INSTITUE OF AMERICA) as "The movement, storage, protection and control of material throughout the manufacturing and distribution process including their consumption and disposal. Effective material handling is the most important part of manufacturing and distribution operation without it final product cannot turn into profit. The handling of material must be performed safely, efficiently, at low cost in timely manner, accurately without damage to the material. The cost of material handling is a significant portion of total production cost estimating average around $20-25 \%$ of total manufacturing cost, so direct cost of material handling cannot be measured. The main factor attributing the material handling cost is wasted time. The second major cost added to material handling is labour cost. In addition increasing labour and time compensation costs make material handling alternative more desirable. The purpose of this paper is to inform the reader about alternative material handling solution that include different type of $\mathrm{AGV}$ and autonomous mobile robot with different application of colored tape type AGV. An Automated guided vehicle is a programmable mobile vehicle used in industrial application to move materials around a manufacturing unit. The first AGV developed by A.M.Barnet (1953) who used overhead wire to navigate the vehicle in grocery shop. The use of AGV has grown enormously since their introduction, the number of area of application and variation type has increased significantly. Recently AGV extended their popularity to other application. Depak punithe (IJRAS august 2013) developed an AGV to betterment public health care system. AGV can used as serving robot in hotel, material handling robot in warehouse and improve the health care system. At manufacturing area AGV are capable to transport all type of material related to manufacturing process. According to Gotte (2000)[5] the usage of AGV will pay off for manufacturing environment (like distribution, transportation, and transshipment ) with repeating transpiration pattern. $\mathrm{He}$ described different available technology for automation in container terminal.

\section{WHAT IS AGV?}

An automated guided vehicle is a programmable mobile vehicle. The automated guided vehicle is used in industrial application to move material around a manufacturing facility. The AGV are capable of transportation task fully automated at low expanses. AGV have to make the system automatic by doing the decision on the path selection. This is done through different method frequency selected mode, path selected mode and vision based mode etc. The central processing system of AGV is issue the steering command and speed command. For the pre defined manufacturing environment the map is saved in the AGV memory and control by stationary control unit of warehouse.

A general AGV system essentially consists of vehicle periperheral on site component as well as stationary control system. The main components of AGV system are

- VEHICLE

- GUIDENCE PATH SYSTEM

- FLOOR CONTROL AND TRAFFIC MANAGEMENT SYSTEM

The faultless interaction of these components ensuring the efficiency of working plant. AGV will guarantee a safe performance of that care of personal as well as the load and surrounding. 


\subsection{VEHICLE}

Vehicle is the central elements of $\mathrm{AGV}$ as they perform the actual transportation task. The vehicle individually according to the specific condition have to be designed and of the environment. They are used in Deepak punithi(2013) designed a AGV to improve health care management system. Li designed line follower AGV for hotel serving robot. Amazon implemented KWIA(Fig.5) robot for automated storage and retrieval system .According to environment AGV can be divided into following categories

1. Driver less train

2. Pallet truck

3. Unit load carrier

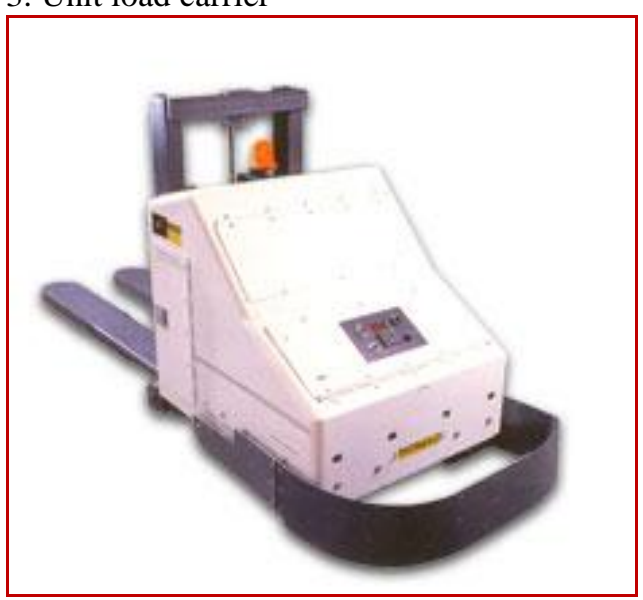

Fig.1Pallet truck

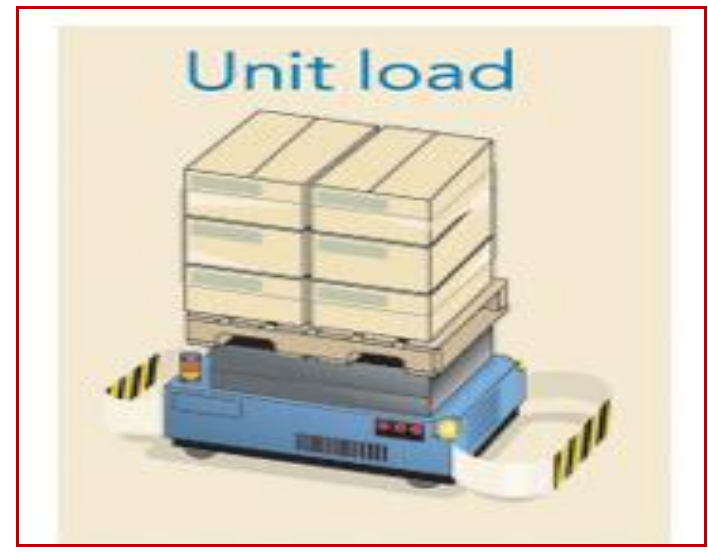

Fig.2(Unitload carrier)

Automated pallet truck(Fig.1) are used to move palletized loads along predetermined route .AGV unit load carriers (Fig.2) are used to move unit load from one station to another station. They are equal for automatic loading and unloading of pallets with mechanized lift platform

\subsection{GUIDENCE PATH SYSTEM}

The vehicle guidance system is the method by which AGV are defined and vehicles are controlled to follow the path ways. AGV use the guidance path system chooses a path based on programmed path. It uses the measurement taken from the sensor and compares them to value given to them by programmer. When AGV approaches a decision point if only has to decide whether follow the path.

Most commonly used guidance technologies in AGV are

1. Landmarked based navigation

2. Behaviors based navigation

3. Vision based navigation

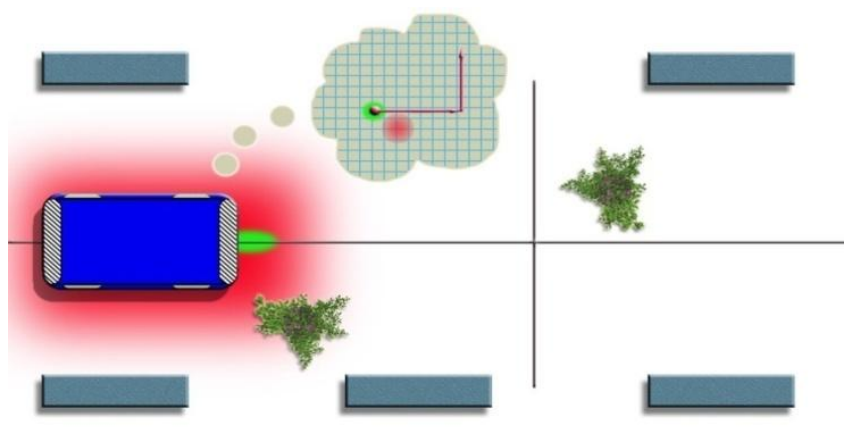

Fig.4 (Landmarked based navigation)

\subsubsection{Landmarked Based Navigation}

Landmarked based navigation technique is based on identification and subsequent recognition of distinct features of an object in the environment that may be prior known or extracted dynamically. The different technologies used in landmarked based navigation are embedded guided wire and taped type system 
(line follower robot). In the embedded wire guided method electrical wires are placed in small channel inside the floor of the work space. The AGV sense the low current with frequency in the range 1-15 kHz for guided the vehicle. The different frequency is used to control the steering motor which makes the required changes in the vehicle direction that to equalize the sensor signal.

The guided tape or line follower AGV is self operating robots that detects and follow a pre defined line drawn on the work floor. To trace the line drawn on the floor the robot used an array sensor which sends the signal to control system of the robot. According to input signal the central system maneuver the robot to stay on the course. While constantly correcting the wrong moves of robot by feedback mechanism thus forming simple and effective loop system. MA Rahman (April 2013) described in his paper AGV driven by a read servo motor guided by a sensor and position controlled by a 3 infrared sensors which connected to a microcontroller PIC16F877A to make the system automatic. By using inertial sensor the AGV maintain collision avoidance with peripheral environment. In the paper by Bajastani (august 2010) described using a line follower robot which describes a cheap and simple navigation technique using microcontroller ATMEGA 16 inside fully automatic environment. This would make the robot 90 turn and junction counting capabilities, to add on the complexity of the problem sensor positioning also play role in operating the robot performance. It uses tunable LDR and LED for navigation system. The tunable LDR improve the performance of robot during different daylight condition.

\subsubsection{Behaviour Navigation System}

This type of paradigm was credited to be suitable unstructured environment as they can incorporate with large number of sensor. The behaviors of the best navigation technique also require high computational power, neural network, genetic algorithm and several combinations of them. Behavior Navigation system uses laser range navigation technology for mobility. Laser range navigation technology is used to determine the vehicle position and navigate the system. In the paper by LOTHER ( 2008) discuss planner scanning technique to improve precision and accuracy. An important step considering laser navigation is to achieve independence of reflection marker, reduced installation cost which will allow overcoming the limitation of the current triangular system developed more than ten years ago.

\subsubsection{Vision Based System}

It is the latest guidance technology which operates without continuously defined the pathway. It used the reckoning navigation system provided position heading and angular velocity of an autonomous mobile robot. Simion has defined the mobile robot as the device that can move in the environment with a certain degree of autonomy. Then navigation associated with available external sensor capturing information from the work space through the proximity measurement and visual image. The research by Malohtra(2003) et. Al has discussed the design of a mobile robot for dynamic environment. A design for the fussy brain for the autonomous robot its integration with both central system and sensor system has been used for detection of the obstacles in warehouse. Ramos have discussed algorithm for vision base system using neural network. Author K.Kishor(2010) has discussed aboutsmooth movement of robot inside workspace.

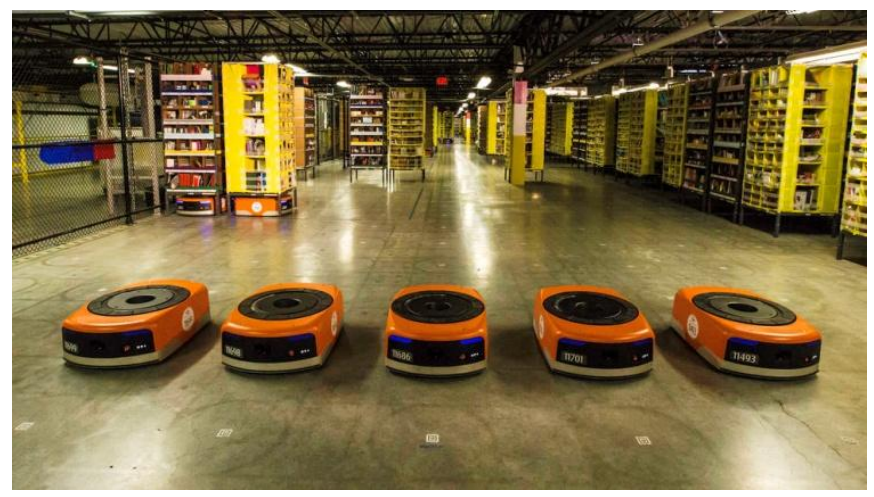

Fig.5: vision based system

In conventional robot the oscillate greatly while attempting to the track the line speed is restricted and the robot oscillate greatly so robot uses much more time and power to navigate the course. The controller calculated its current position, it then calculated error from the target position when error is high the motor will make a hard turn, If the error will low the motor ill make the smaller adjustment so the magnitude of the turn is 
proportional to the error. The derivative control is implemented to mitigate the oscillating effective overtime.

The basic idea of the algorithm is

Error $=$ Target position - Current position;

$\mathrm{P}=$ Error $\times \mathrm{Kp}$

$\mathrm{D}=$ Error - Previous Error; store changes in error to deviated

Correction $=\mathrm{P}+\mathrm{D}$

$\mathrm{Kp}=$ error time proportional constant

Correction term is applied for the left and left motor speed.

The constant in the algorithm were adjusted to minimize overshoot and oscillation at the highest speed possible by adjusting, the proportional constant.

\subsection{FLOOR CONTROL AND TRAFFIC MANGEMENT SYSTEM}

To operate efficiently and increasing the productivity of AGV, the vehicle should be well managed .Delivery task must be allocated to minimizing the waiting time at load/unload station. The traffic control managed by AGV using un board vehicle sensing and zone control. In the paper of kumanan(2010) described the multi objective task scheduling of AGV in Flexible manufacturing environment using nontraditional optimization algorithm. He described to algorithm control the traffic inside the workspace. Genetic algorithm is searched based algorithm of natural selection process. ACO algorithm is used to find the combination near optimum schedule in which it satisfy both the balancing of task among the AGV based on the travel time and minimize time. For efficient control two type of control system are used inside the workplace Fig. 6 .

1. Stationary control system

2. Peripheral control system

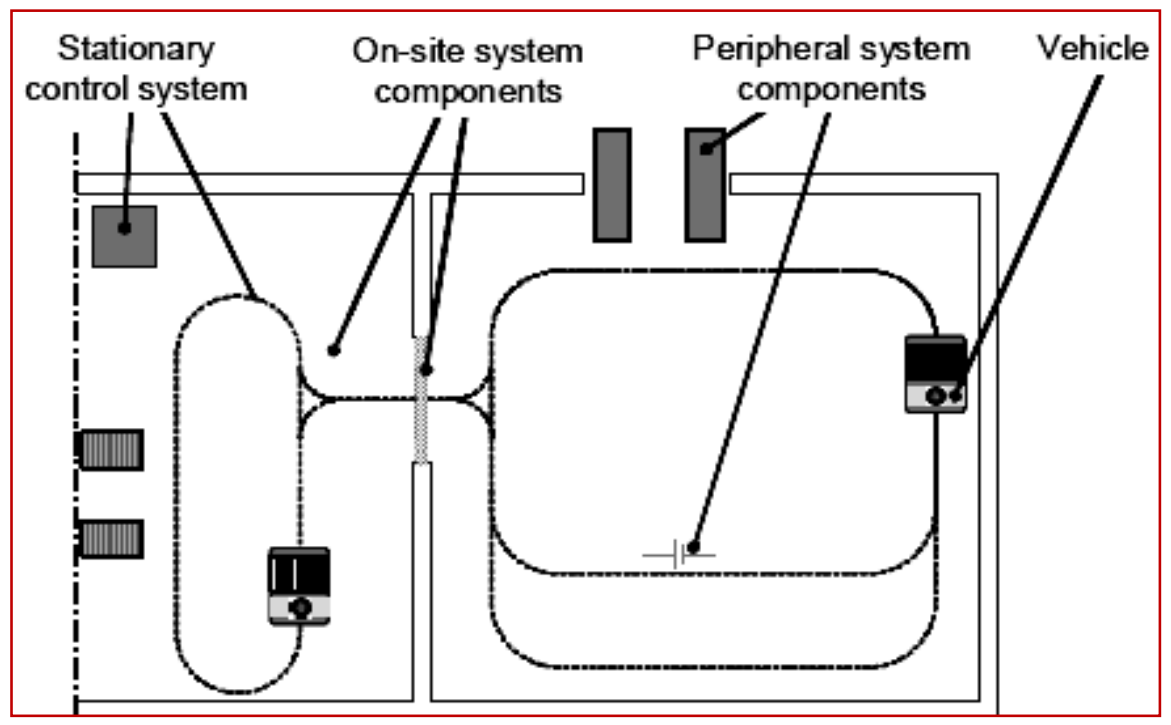

Fig.6 (Control system of AVG)

The stationary control system covers all super ordinate control components. It maintains the administration of transportation order, optimization of schedule communication with other control system via pre defined interface. It is also in charge of consumer interaction and provides auxiliary function such as graphical visualization and statistical analysis. Peripheral control systems manage the various on board equipment of the vehicle example battery loading mechanism and load transfer mechanism.

Mathematical model can able to describe the operation of AVG inside the manufacturing/ warehouse unit. Efficiency of AGV can measure by efficient drive time of AGV from loading to unloading cycle. . For this mathematical model we can assume that AGV moves in constant velocity throughout the environment and ignore the effect of acceleration deceleration and other speed difference. The time for a typical deliver cycle system of $\mathrm{AGV}$ is

1. Loading at the pickup station

2. Travel time to the drop-off station

3. Unloading at drop off station 
4. Empty travel time

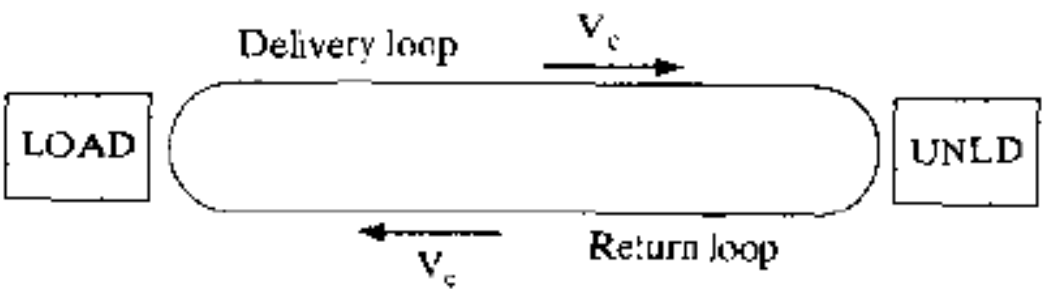

Fig.7 (Path of AVG)

$: \mathbf{T}_{\mathrm{e}}=\mathbf{T}_{\mathbf{l}}+\mathbf{L}_{\mathrm{d}} / \mathrm{v}+\mathbf{T}_{\mathrm{u}}+\mathrm{L}_{\mathrm{e}} / \mathrm{v}$

$\mathrm{T}_{\mathrm{e}}=$ delivery cycle time (min/delivery)

$\mathrm{T}_{1}=$ time to load $(\mathrm{min})$

$\mathrm{L}_{\mathrm{d}}=$ distance travel load to unload station

$\mathrm{v}=$ carrier velocity

$\mathrm{T}_{\mathrm{u}}=$ time to unloading station

$\mathrm{L}_{\mathrm{e}}=$ distance the vehicle travel until the start of the next delivery station

To find number of vehicle inside a environment

$$
\mathbf{n}=\frac{W L}{A T}
$$

$\mathrm{n}=$ number of vehicle

$\mathrm{WL}=$ work load $(\mathrm{min})$

$\mathrm{AT}=$ available time $(\min )$

To find total work load time or the total amount of work express in term of time so

$$
\mathrm{WL}=\mathrm{R}_{\mathrm{f}} \mathrm{T}_{\mathrm{a}}
$$

$\mathrm{R}_{\mathrm{f}}=$ total deliver constant per hour for the system

AT is defined by available time per hour per vehicle

$\mathrm{AT}=60 \mathrm{~A} \mathrm{~T} \mathrm{E}$

Using the above equation we can find how many AGV can fit in certain workspace. It calculate the time require for completing a task .so by considering this equation we can optimize the ideal time of AGV.

\section{APPLICATION}

Autonomy is the key factor for using AVG in different field. It will achieve high degree of accuracy and precision which will lead to minimize the error of the complete system and improved lead time. Flexibility is the key issue which will help AGV to be popular from other material handling system. The AGV not only used inside the production house but also increase its premises to other service sector.

1. Material handling: used in highly automotive and electronic factories, loading unloading station

2. Warehouse: used in e commerce warehouse for transporting the material 
3. Commercial: baggage transport inside airport, supermarket, mall, floor treatment like wash ,swap, scrub unpleasant job like washing warehouse

4. Energy and defense: transport the material human unreachable place, bomb and mine mapping, retrieval and disposal nuclear plant inspection, and steam generator, pipeline inspection

5. Medical service:deliver food water and medicine ,administrative reports ,handling hazardous material, disposal of biological waste

6. Personal care: Assistance for handicapped and early assistance with personal hygiene

\section{CONCLUSION}

There are several possible directions for further research. We can improved the guided tape type AGV utilizing better navigation technique. It can be adopted any environment and cheap among autonomous robot. There is significant amount of difference between theoretical and practical work cycle value of time which can be optimized by adopting different methodology. In addition, one could think of a relaxation of the tokenholding requirement in the traffic control scheme so that multiple vehicles can leave different at-crossing zones simultaneously, and hence the performance of the AGV system can be improved.

\section{REFERENCES}

[1] Deepak Punetha, Neeraj Kumar, Vartika Mehta Development and Applications of LineFollowing Robot Based Health CareManagement System, IJARCET volume 2 issue 82013

[2] Rajeev K piyre,Member; LAENG, and Ravinesh Singh. Wireless Control of an Automated Guided Vehicle. In Proceeding og the International Multiconference of Engineering and Computer Scientists 2011 Vol II IMECS 2011, March 16-18, 2011, Hong Kong, China

[3] M. Zafri Baharuddin, Izham Z. Abidin, S. Sulaiman Kaja Mohideen, Yap Keem Siah, Jeffrey Tan Too Chuan Analysis of Line Sensor Configuration for the Advanced Line Follower Robot

[4] K Kishor Desgine Of Automated Guided Vehicel ， IJARC Volume 3, Issue 1, January- April (2012)

[5] Feng, L., Koren, Y., and Borenstien, J., "A Cross-Coupling Motion Controller for Mobile Robots," IEEE Journal of Control Systems, December, 35-43 (1993)

[6] Lothar schulze ,Sebasitian Behiling “ Automated Guided Vehicle System: a Driver for Increased Business Performance” IMECS 2008 19-21 March 2008 hongkong

[7] M.A.Rahaman "Design And Fabrication Of Line Follower Robot" Asian journal of applied science and engineering voluem2 2013

[8] Udhayakumar ,Kumanan s “Task Scheduling Of Agv In FMS Using Nontraditional Optimization Techniques”Intsimuljmodel 2010 ISSN 1726-4529

[9] Bajestani, S.E.M., Vosoughinia, A., "Technical Report of Building a Line Follower Robot" International Conference on Electronics and Information Engineering (ICEIE 2010), vol 1,pp v1-1 v1-5,2010

[10] Borenstien, J., and Feng, L., "Measurement and Correction of Systematic Odometry Errors in Mobile Robots," IEEE Transactions on Robotics and Automation, 12, 5,869-880 (1996).

[11] ASME, Safety Standard for Guided Industrial Vehicles and Automated Functions of Manned Industrial Vehicles, The American Society of Mechanical Engineers, NewYork, 1993.

[12] Thirumurugan. J, Kartheeswaran. G, Vinoth. M, Vishwanathan. M, Line following robot for library inventorymanagement system, International conference on Emerging trends in Robotics and CommunicationTechnologies, 2010, 1-3

[13] Priyam A. Parikh, Keyur D. Joshi, Saurin Sheth Color Guided Vehicle - An Intelligent MaterialHandling Mechatronic System

[14] Mohanraj, MICROCONTROLLER BASED AN AUTONOMOUS WIRELESSLINE TRACKING ROBOT International Journal of Advanced Engineering Research and Studies E-ISSN2249-8974.

[15] De Koster, R., Le-Duc, T., and Roodbergen, K.J. (2007), Design and control of warehouse orderpicking: a literature review. European Journal of Operational Research 182(2), 481-501.

[16] Kelly, A., Nagy, B. "Reactive Nonholonomic Trajectory Generation via Parametric Optimal Control", The International Journal of Robotics Research, Vol. 22, No. 7-8, 583-601 (2003)

[17] Kelly, A. Unnikrishnan, R., "A Constrained Optimization Approach to Globally Consistent Mapping”, Proceedings of the IEEE/RSJ International Conference on Intelligent Robots and Systems (IROS 2002). Lausanne, Switzerland, Sept. 2002.

[18] Kelly, A. Unnikrishnan, R., "Efficient Construction of Optimal and Consistent LADAR Maps using Pose Network Topology and Nonlinear Programming, 11th International Symposium of Robotics Research (ISRR'2003), Sienna, Italy, November 2003.

[19] Lowe, D. G., "Distinctive Image Features fromScale-Invariant Keypoints", International Journal of Computer Vision, 60,

[20] Bajestani, S.E.M., Vosoughinia, A., "Technical Report of Building a Line Follower Robot" International Conference on Electronics and Information Engineering (ICEIE 2010), vol 1,pp v1-1 v1-5,2010.

[21] Colak, I., Yildirim, D.,"Evolving a Line Following Robot to use in shopping centers for entertainment",Industrial Electronics, 2009. IECON '09. 35th Annual Conference of IEEE,pp.3803 - 3807,3-5 Nov. 2009.

[22] Mahadevan, B., Narendran, T.T., 1993. Estimation of number of AGVs for an FMS: An analytical model. International Journal of Production Research 31 (7), 1655-1670.

[23] Malhotra Rajiv, Sarkar Atri; —Development of a Fuzzy Logic Based Mobile Robot for Dynamic Obstacle Avoidance and Goal Acquisition in an Unstructured Environmentl; Proceedings of IEEE/ASME, International Conference on Advanced Intelligent Mechatronics, pp.235-247, 2003 
[24] M. Zafri Baharuddin, Izham Z. Abidin, S. Sulaiman Kaja Mohideen, Yap Keem Siah, Jeffrey Tan Too Chuan,"Analysis of Line Sensor Configuration for the Advanced Line Follower Robot",University Tenaga Nasional.

[25] Miller Peter, "Building a Two Wheeled Balancing Robot", University ofSouthern Queensland, Faculty of Engineering and Surveying. Retrieved Nov 18, 2008.

[26] Nor Maniha Abdul Ghani, Faradila Naim, Tan Piow Yon, "Two Wheels Balancing Robot with Line Following Capability," World Academy of Science, Engineering and Technology, pp-634-638, 2011.

[27] Saadettin Erhan Kesen, Omer Faruk Baykoc. Simulation of Automated Guided Vehicle (AGV) Systems Based on just-in-time (JIT) Philosophy in a job-shop Environment. Available online at www.Sciencedirect.com_Simulation Modelling Practice and Theory 15 (2007) 272-284

[28] Montague, J., "Why Not wireless?" Control Engineering, October, 20-26 (2001).

[29] Kelly, A., Kim, W., Helmick, D, "Model-Based Object Pose Refinement For Terrestrial and Space Autonomy", In Proceeedings of 6th International Symposium on Artificial Intelligence, Robotics and Automation in Space (ISAIRAS 01), Montreal, Quebec, Canada June 18,2001

[30] Forger, G., "Non-wire Guidance Systems Take Control of AGVs," Modern Material Handling, August, 58-59 (1998).

[31] Kelly, A., Kim, W., Helmick, D, "Model-Based Object Pose Refinement For Terrestrial and Space Autonomy", In Proceeedings of 6th International Symposium on Artificial Intelligence, Robotics and Automation in Space (ISAIRAS 01), Montreal, Quebec, Canada June 18,2001.

[32] Czosnyka M, Smielewski P, Kirkpatrick P, et al. Continuous monitoring of cerebrovascular pressure-reactivity in head injury. Acta Neurochir Suppl. 1998;71:74-7.

[33] All figure from Google and Mickel p.groover

[34] Mickel P. groover ,Fundamentals oj Modem Manufacturing: Materials, Processes, and Systems, Prentice Hall, 1996

[35] Mickel P. groover CAD/CAM: Computer-Aided Design and Manufacturing, Prentice Hall. 